\title{
Migração e telecomunicações: tecnologias e famílias transnacionais na França e África Ocidental"
}

\author{
Carolyn Sargent** \\ Stephanie Larchance-Kim*** \\ Samba Yatera****
}

\begin{abstract}
Resumo
Através da comparação de conexões e interações entre França $e$ África Ocidental e do uso das telecomunicações por imigrantes chegando à França em períodos diversos entre 1965 e 2005, este artigo demonstra a relevância dessas tecnologias de comunicação na (re)definição da distância social e na facilitação do envolvimento continuado de migrantes na tomada de decisões familiares nas suas comunidades de origem.
\end{abstract}

Palauras-chave: Conexões Familiares, Imigrantes Africanos, Comunicação, Tecnologia.

\footnotetext{
* Recebido para publicação em maio de 2007, aceito em agosto de 2007 (Tradução do inglês: Ethon Fonseca; Revisão: Cláudia Fonseca).

*** Antropóloga, professora de Antropologia na Southern Methodist University, Dallas, USA. csargent@mail.smu.edu

**** Candidata doutoral em antropologia na Southern Methodist University, Dallas, USA.slarchan@smu.edu

***** Sociólogo, pesquisador do Groupe de Recherche et de Réalisation pour le Développement du Tiers-Monde (GRDR), Paris, França. yaterasamba@free.fr
} 
Migração e telecomunicações

Migration and Telecommunications:

Technologies and Transnational Families in France and West Africa

\begin{abstract}
Through the comparison of social connections and interactions between France and West Africa and the use of telecommunications by migrants arriving in France at differing periods between 1965 and 2005, this article demonstrates the significance of these communication technologies in (re)defining social distance and facilitating the continued involvement of migrants in family decision making in the original communities.
\end{abstract}

Key Words: Family Connections, African Immigrants, Communication, Technology. 
No discurso acadêmico, como no popular, é hoje lugar comum dizer que as novas tecnologias da informação $e$ comunicação incidiram sobre todos os domínios da vida social $e$ que elas podem, afinal, homogeneizar comportamentos econômicos, culturais e sociais (Hannerz, 1989; Lockwood, 2004:56). A florescente literatura nas ciências sociais sobre a globalização produziu extensas discussões teóricas sobre como as tecnologias da comunicação modelam processos transnacionais $e$ transformam relações sociais (Burawoy et alii, 2000; Inda e Rosaldo, 2002). Contudo, pesquisa etnográfica fundamentada que documente o verdadeiro impacto dessas tecnologias na vida dos indivíduos e nas suas relações familiares é relativamente rara.

$\mathrm{O}$ presente estudo elabora justamente essas questões no contexto da crescente acessibilidade de diversas formas de telecomunicações para os imigrantes da África Ocidental na França. No decorrer da pesquisa entre imigrantes do Vale do Rio Senegal (Mali, Mauritânia, Senegal), residindo em Paris, França, entre 1998-2005, tornou-se aparente que a difusão das tecnologias de comunicação cada vez mais eficientes e acessíveis desempenhou um papel importante na vida quotidiana dos imigrantes e das suas comunidades domésticas. ${ }^{1}$ Este tema surgiu espontaneamente em interações entre pesquisadores e pessoas

\footnotetext{
${ }^{1}$ As informações aqui relatadas foram levantadas como parte de um estudo mais amplo da organização de famílias migrantes, reprodução e o estado, financiado pelo National Science Foundation BCS 0105192 e pelo Wenner-Gren Foundation for Anthropological Research. Entre os colaboradores desta pesquisa estão Carolyn Sargent, Departamento de Antropologia, Southern Methodist University; Dennis Cordell, Departamento de História, Southern Methodist University; Samba Yatera, Sociólogo, Pesquisador do Groupe de Recherche et de Realisation pour le Developpement du Tiers-Monde (GRDR), Paris; Ismael Maiga, Professor de Sociolingüística, Universidade de Paris VIII, e Stephanie Larchanche-Kim, candidata doutoral em antropologia, SMU. Agradecemos o apoio do Professor Yves Charbit, Diretor do Centre Population et Interdisciplinarite, Universidade de Paris, e do Professor Didier Fassin da École des Hautes Etudes en Sciences Sociales. Madame Bintou Baradji e Madame Tiguide Yatera foram assistentes de pesquisa excepcionais.
} 
Migração e telecomunicações

entrevistadas, em referência às relações com membros da família "em casa" (au pays). Discussões com informantes sobre questões sociais, tais como a falta de moradia, poligamia, desemprego e o sistema público de saúde, inesperadamente provocavam comentários sobre as vantagens e desvantagens de freqüentes comunicações com a família estendida na África Ocidental.

Enquanto parecia inicialmente (e intuitivamente) que as telecomunicações diminuiriam o peso emocional de estar longe da família e do lugar de origem, tornou-se cada vez mais evidente que a facilidade em comunicar-se também parecia reforçar as relações de dependência de comunidades na África dos que migraram para a França. Com a proliferação de telefones, fax, acessos à internet, fitas de áudio e vídeo cassetes, demandas por suporte financeiro e assistência social se tornaram mais do que nunca freqüentes e urgentes.

Para melhor entender o impacto desses modos de comunicação nas relações sociais de migrantes, especialmente daqueles com parentes, procuramos conduzir nosso estudo das telecomunicações em ambos os extremos do espectro, isto é, nas comunidades que enviam e nas que recebem pessoas. Por um lado, enfocamos o papel das telecomunicações na manutenção de vínculos entre migrantes do Vale do Rio Senegal residindo em Paris e suas comunidades de origem. O exame das conexões sociais e interações entre França e África Ocidental e do uso das telecomunicações por imigrantes chegando à França, em diferentes períodos entre 1965 e 2002, demonstrará as importantes funções desses modos de comunicação na definição da distância social e na viabilização do envolvimento contínuo de migrantes na tomada de decisões das famílias em suas comunidades de origem.

Além disso, através do rápido estudo das telecomunicações usadas em duas áreas de Bamako, Mali, nós tentamos sondar a acessibilidade e viabilidade econômica para a população das tecnologias de comunicação, bem como sua representação $e$ valorização no discurso popular local. Em paralelo com o estudo em Paris, nós também exploramos perspectivas locais sobre os 
aspectos benéficos e problemáticos de linhas telefônicas, telefones celulares, internet cafés e outros modos de telecomunicações para a manutenção de laços transnacionais de parentesco.

\section{Marco teórico}

Estudiosos de diversas disciplinas têm explorado os fluxos transacionais de população, capital, bens e telecomunicações que constituem a globalização. Muitas dessas pesquisas abordaram processos globais em alto nível de abstração. Antropólogos e sociólogos podem oferecer uma visão singular do impacto local da globalização, demonstrando como indivíduos, famílias e comunidades locais interpretam, negociam e interagem criativamente no contexto desses processos transnacionais. Ao fazer isto, tais estudos fundamentados também podem demonstrar que as práticas transnacionais não estão livres de constrangimentos contextuais, mas determinadas por pessoas específicas, em localidades específicas e em momentos históricos específicos (Smith e Guarnizo, 1999:11).

A globalização intensificou contatos e conexões, produzindo um mundo interligado de troca e aculturação persistentes (Inda e Rosaldo, 2002:2). A migração transnacional, um importante aspecto da globalização, transformou a dimensão espacial da vida social cotidiana, separando membros da família e removendo relações sociais dos contextos locais de interação (Giddens, 1990:14-18). Assim, a modernidade fatalmente tolheu as interações face a face para aqueles que estão mergulhados no mundo desterritorializado do migrante transnacional (Appadurai, 1966:4). O impacto da desterritorialização desencadeou, notavelmente entre antropólogos, uma nova avaliação dos conceitos de identidade e cultura, pondo em questão a estabilidade destes, bem como de sua relação com um único Estado-Nação ou uma única comunidade imaginada (Ong, 1993). Assim, boa parte da literatura sobre globalização enfocou temas tais como o nacionalismo póscolonial e a redefinição de cidadania (Id., 1999), a crescente 
Migração e telecomunicações

informalização da economia e o impacto deste na vida dos migrantes urbanos (Sassen, 1999) ou nas políticas transnacionais (Smith e Guarnizo, 1999).

Appadurai (1996:3) observou, como aspecto central da globalização, que a mídia e a migração produziram um efeito dialético, no qual as percepções dos migrantes sobre si $e$ sua comunidade são transformadas pela televisão, cinema, vídeo, computadores e telefones. Conseqüentemente, as telecomunicações e a mídia têm o potencial de transformar o discurso do dia-a-dia e de permitir às redes de parentesco $e$ amigos manter conexões íntimas. Aqueles que migram e aqueles que permanecem na comunidade de origem são capazes de formularem planos e estratégias com o auxílio de telefones, fitas de áudio, fax e vídeos, assim, a comunicação de massa e os múltiplos modos de telecomunicação transcendem fronteiras nacionais, ligando redes domésticas através de grandes distâncias.

A migração da África Ocidental para a França representa o movimento pós Segunda Guerra Mundial de populações de lugares menos afluentes para os mais afluentes, culminando na convergência e "colisão" de culturas distintas (Inda e Rosaldo, 2002). Enquanto reconhecemos a importância das análises acadêmicas dos processos econômicos, políticos e culturais em grande escala, sugerimos que é igualmente importante documentar como o local e o global se entrecruzam. A etnografia tem muito a contribuir no enriquecimento das interpretações do que realmente significa globalização na prática, por exemplo, nas implicações da migração transnacional para a organização familiar $e$ os próprios significados associados com o conceito de família (Burawoy et alii, 2000).

Este estudo das comunicações e relações sociais dos migrantes mostra que, atualmente, os imigrantes acham cada vez mais fácil manter redes de conexão, especialmente através de telefones (via satélites, cabos ou telefones celulares) e fax. As conexões atuais são mais intensas $e$ freqüentes do que as possibilitadas por tecnologias de telecomunicações há quarenta 
anos atrás. Atualmente, a distância e a separação geográfica são muito menos determinantes do que no passado. Neste artigo, porém, enfatizamos que a difusão das telecomunicações envolve mais do que a compressão de tempo e espaço. De fato, enquanto ela reforça a produção, a criatividade cultural $e$ as obras da imaginação, ela também carrega as comunidades imigrantes de obrigações crescentes para com a família e amigos na comunidade de onde saíram (Castells, 1999:90).

Em outras palavras, a expansão das telecomunicações trouxe novos constrangimentos sociais. $\mathrm{O}$ imaginário mediado pelas comunicações de massa também produz, para as famílias de migrantes que permanecem "em casa", ideais de condições de vida em países ricos que não correspondem necessariamente à realidade. Isto produz, por sua vez, constrangimentos psicológicos para os próprios imigrantes que não querem decepcionar ou preocupar seus parentes na comunidade de origem.

\section{Caso 1: telecomunicações e migrantes da África Ocidental em Paris}

\section{Amostragem}

Noventa migrantes do Vale do Rio Senegal foram entrevistados para determinar se e como mantêm conexões com família e amigos na África Ocidental. Entrevistas foram conduzidas em diversos locais para levantar informação de uma amostra territorializada da população. Estes lugares incluem uma área de ocupação (squatters) conhecida como a "Maison dês Ensembles"; um hospital público voltado a populações migratórias da África Ocidental e do Norte; um subúrbio ao leste de Paris com uma concentração substancial de imigrantes da África Ocidental; e cinco pensões de homens trabalhadores. Essa combinação de lugares nos permitiu entrevistar quarenta $e$ nove homens $e$ quarenta e uma mulheres. 
Migração e telecomunicações

\section{Informações coletadas e análise}

Informantes foram questionados usando o roteiro de uma entrevista semi-estruturada cunhada para revelar informação demográfica básica (idade, sexo, estatuto marital e empregatício, tempo de residência na França) e relações com comunidades de origem. Para determinar a relevância de diversos modos de comunicações em suas vidas diárias, colocamos aos informantes uma série de questões incluindo a freqüência de voltas "para casa", meios preferenciais de comunicação e razões por tal preferência, bem como detalhes sobre utilização de telefones. Tendo constatado que o contato telefônico é amplamente preferido, logo nos interessamos pela determinação da freqüência de chamadas, as razões para as chamadas, os tipos de telefone de quem chama e de quem recebe as ligações e os montantes gastos em chamadas.

As informações coletadas foram analisadas utilizando SPSS. Olhamos inicialmente estatísticas descritivas estabelecendo freqüências para todas as variáveis coletadas. Algumas variáveis nominais - tais como "razões para ligar para casa" - também foram quantificadas e transformadas em representações gráficas. Esse primeiro passo nos propiciou tecer inferências básicas $e$ decidir quais correlações queríamos investigar. Para esta investigação de correlações entre variáveis "demográficas" e o uso de telecomunicações, selecionamos os casos de interesse $e$ cruzamos com freqüências adicionais. A análise desses achados nos levou a enfocar certas associações observadas, tais como diferenças de gênero, que foram testadas com regressões de logística binária. Além disso, analisamos narrativas de migrantes para - atentando para termos e conceitos freqüentemente utilizados - identificar temas comuns.

\section{Resultados do levantamento}

A amostragem total de entrevistados nos diversos lugares ia dos 16 aos 61 anos, com uma média de 36. Questões tocantes à residência e organização familiar indicaram que $74,7 \%$ eram 
casados, ainda que suas famílias não estivessem necessariamente residindo na França à época. Aproximadamente 54\% de nossos informantes estavam convivendo com parentes, ao passo que $41,6 \%$ (todos homens) estavam vivendo em foyers (pensões para trabalhadores); os outros viviam com amigos, em casa de estudante ou sozinho. Quase a metade $(46,1 \%)$ dos entrevistados tinha emprego, mas 50,6\% não tinham emprego regular; $3,4 \%$ declararam que eles estavam trabalhando no mercado negro. Muitos daqueles sem emprego regular, presumivelmente, também trabalhavam intermitentemente no mercado negro.

Em nossa investigação de conexões entre migrantes e suas comunidades de origem, nós buscamos determinar a freqüência de visitas à família, bem como os modos preferidos de se comunicar. Apenas $31 \%$ dos migrantes disseram que visitavam "regularmente" seus lares, donde a importância do uso das telecomunicações. O sentido específico de "regularmente" foi difícil de estabelecer. Mais da metade dos imigrantes disse que raramente ou nunca iam para casa, outros declararam que "freqüentemente" faziam visitas - o que eles definiram como em intervalos de dois ou três anos. Os entrevistados freqüentemente assinalaram que o custo das passagens aéreas para si e outros membros da família, bem como os custos significativos de presentes para os parentes, eram proibitivos. Assim, apesar do desejo de voltar "para casa" anualmente, ou ao menos para visitas bianuais, nem sempre conseguiam ir.

Por outro lado, $98 \%$ declararam receber freqüentes notícias de casa. Os meios mais populares de comunicação eram, sem surpresa, telefone $(74 \%)$ ou uma combinação de correio e telefone (11\%) (Figura 1). Uma minoria preferia apenas correio, correio e internet, telefone e internet ou a ocasional troca de fitas de áudio. Embora ciber cafés sejam numerosos no centro de Paris e nos subúrbios de vizinhança imigrante, apenas $3 \%$ de nossa amostragem declarou preferir a internet para manter contato com parentes e amigos; um total de aproximadamente 6\% utilizava, por vezes, a internet. 
Migração e telecomunicações

De oito informantes que discutiram seu uso da internet, três eram mulheres, todas tendo completado estudos secundários, duas das quais tinham alguma educação pós-secundária. Elas tinham 18, 31, e 46 anos e todas viviam com família em Paris. Estas mulheres também tinham irmãs ou outros parentes em Mali ou Senegal com acesso a computador (na universidade ou num estabelecimento comercial). Em contraposição, quatro dos cinco homens viviam numa pensão de homens trabalhadores, um com sua família, e suas idades variavam de 27 a 47 anos. Um era estudante universitário, outro tinha freqüentado o segundo colegial e três tinham amigos em Paris com acesso a computador no serviço. Dessa forma, eles podiam mandar mensagens de email à família na África sem pagar, ao menos ocasionalmente. Como dois homens notaram, eles preferiam telefonar, mas usavam o modo de comunicação menos caro.

$\mathrm{Na}$ amostragem geral, uma esmagadora preferência por telefonemas emergiu, mesmo entre aqueles que por vezes se valia de outras tecnologias por razões de custo ou conveniência periódica. Quando indagados sobre sua preferência por telefones, os informantes responderam consistentemente que telefones são comparados particularmente com cartas - rápidos, fáceis e é possível escutar a voz de membros da família, o que é muito comovente. Aqueles que preferiam contar com as cartas o faziam porque não podiam arcar com os custos de telefonar.

Uma resposta interessante a respeito das vantagens do telefone era que este propicia privacidade. Ao enviar uma carta à família, se não houver parente letrado, alguém de fora da família imediata é requisitado a ler a carta e pode espalhar informação à comunidade. Além disso, é difícil enviar uma carta a um membro da família sem que os outros tenham acesso às informações. $\mathrm{O}$ tema da privacidade foi citado como problemático para migrantes em Paris, bem como para seus parentes na África Ocidental.

Por exemplo, um profissional oriundo de Mali (professor universitário), que periodicamente se prontificava a ler cartas numa pensão de trabalhadores para os hóspedes analfabetos, 
descreveu os casos sensíveis em que ele se viu metido. Numa ocasião, ele começou a ler uma carta enviada a um residente de pensão que tinha em torno de 60 anos. A carta começava, "Agraciado seja ao Deus, sua esposa mais jovem deu à luz um filho". O destinatário ouviu o restante da missiva sem comentário. Depois, ele disse ao professor, "você sabe que eu não estive em casa para ver minha mulher em três anos?" Ele então ditou uma resposta, cuidadosamente frisando sua reação que indicava reivindicar o filho. Tais situações ilustram o risco de disseminar informação "privada" que cartas possam trazer para aqueles que necessitam de assistência na sua leitura.

Da mesma forma, fitas de áudio, mesmo propiciando aos migrantes e seus familiares a obtenção de relatos detalhados de eventos e a escuta das vozes de seus amados, tampouco são o ideal para a transmissão de informação confidencial. Telefones servem, assim, a múltiplas funções, uma delas é facilitar a transmissão de notícias delicadas a um número limitado de indivíduos, protegendo o que um informante se referiu como "os segredos da casa".

Os gastos com as freqüentes chamadas telefônicas, até mesmo por aqueles que estão em situação economicamente precária, são significativos. Quase 24\% telefonavam para casa semanalmente, $35 \%$ telefonavam à família uma ou duas vezes por mês, e $26 \%$ telefonavam duas ou três vezes por semana. A quantia média gasta mensalmente com telefonemas era de quarenta e sete euros, com um máximo de 240 euros. Quando comparamos a quantia gasta por homens e por mulheres, vemos que mulheres gastam um pouco menos (36 euros) que homens (55 euros).

É interessante notar que o emprego tinha fraca correlação com gastos (Tabela 1). Aqueles que tinham trabalho gastavam, em média, 48 euros mensais e aqueles sem trabalho uma média de 44 euros por mês. Novamente, esta relação entre "chamar freqüentemente" e "situação de trabalho" era insignificante, mostrando que migrantes, de fato, telefonam para casa freqüentemente a despeito de sua posição econômica. Do mesmo 
Migração e telecomunicações

modo, a relação entre "enviar dinheiro" e "situação de trabalho" provou ser pouco significativa. Narrativas indicaram que migrantes sentiam-se obrigados a ajudar financeiramente suas famílias na terra de origem, a despeito de quão restritas são suas finanças, ou mesmo se possuíam ou não emprego regular. Um imigrante ilegal, de 33 anos, relatou que sua mulher vive em Bamako e teve um problema sério de saúde. Ele teve de pagar por sua hospitalização, embora ele esteja sem emprego ou papéis. "Se você não tem dinheiro [e acontece uma emergência] você é obrigado a fazer coisas estúpidas (faire des conneries)", ele disse.

$\mathrm{O}$ prazo limite de residência na França era de 13 anos. $\mathrm{O}$ prazo de residência provou afetar a freqüência com que migrantes enviavam dinheiro para suas famílias na África. Assim, uma associação entre "enviar dinheiro" $e$ "anos de residência na França" dos migrantes foi estatisticamente significativa $(p<.05)$. Resultados do teste de regressão logística indicaram uma alta previsibilidade de não envio de dinheiro à medida que aumenta o tempo em que os migrantes ficam na França; isso sugere que eles possam se sentir menos conectados às comunidades domésticas na África Ocidental ou, alternativamente, que possuem mais parentes na Europa.

Aproximadamente metade dos nossos informantes conseguia cartão telefônico em pensão de trabalhador ou tinha uma loja de cartão telefônico que freqüentavam. A maioria das suas famílias na África Ocidental tinha um telefone (81\%) e aqueles que não tinham eram contatados por meio do telefone de outra família, um telefone da comunidade local por satélite, ou uma linha telefônica da região. Um número relativamente alto de comunidades em Mali e Mauritânia é equipado com linhas terrestres (36\%), bem como com telefones celulares (13\%). Muitas comunidades se comunicam através destes meios (35\%). O acesso às telecomunicações melhorou até mesmo nos povoados mais remotos, principalmente devido aos investimentos de associações de emigrantes em Paris na construção de linhas terrestres $e$ ao financiamento de estações telefônicas via satélite. 
Uma associação de Africanos em Paris, por exemplo, gastou cerca de \$10 000 na instalação de um telefone via satélite numa remota comunidade da Mauritânia. O sistema serve a todos da região. Quando um chamado é recebido de Paris, o operador telefônico contata o destinatário para indicar quando a pessoa que chamou irá ligar novamente. O destinatário deve aguardar, então, na cabine. Esse sistema, embora seja descrito como bemsucedido, está em vias de tornar-se ultrapassado com a rápida proliferação de telefones celulares individuais.

Nesta pesquisa, investigamos quem os migrantes contatam com maior freqüência (por telefone, correios ou outros meios) na sua sociedade de origem e para quais propósitos. Na absoluta maioria dos casos, as chamadas eram feitas a membros da família e ocasionalmente a amigos. Pais, mães, esposas, irmãos e filhos atendiam a maioria das chamadas. Mulheres, talvez não surpreendentemente, tendiam a telefonar a seus filhos que estavam aos cuidados de parentes $e$ a suas mães, irmãs $e$ tias. Telefonar para os pais era considerado mais importante do que telefonar para o esposo; como disse um homem, na faixa dos 30 anos, entrevistado num edifício ocupado (squatter): "É sempre possível encontrar outra noiva ou esposa, mas mãe só tem uma". Enquanto todo mundo disse telefonar para dar e receber "notícias", mais da metade também disse que usava o telefone para ajudar a resolver problemas familiares e para confirmar com antecedência o envio de dinheiro à família (Figura 2). Uma interessante diferença de gênero surgiu: homens e mulheres usavam telecomunicações para acertar o envio de dinheiro ao lar, mas homens telefonam para resolver problemas mais do que mulheres. Essa associação era estatisticamente significativa $(\mathrm{p}<.05$; ver Figura 3).

Telefones são percebidos, ao mesmo tempo, como vantajosos e problemáticos. Por exemplo, aqueles migrantes que chegaram à França no final dos anos 1960, 70 ou mesmo nos 1980 comentaram sobre o tempo necessário para enviar e receber cartas naquela época. Notícias de uma doença ou morte 
Migração e telecomunicações

raramente eram imediatas $e$, freqüentemente, eram recebidas meses após o ocorrido. Presentes ou pedidos eram, por vezes, transmitidos por amigos ou familiares que voltavam à África Ocidental para visitas, mas estas eram irregulares. Para esta geração mais velha, o contato instantâneo, o prazer de ouvir as vozes da família e passar por cima de intermediários para enviar e receber informação confidencial são benefícios significativos do acesso atual aos telefones.

Uma entrevistada que chegou à França no início dos anos 1970 observou: "Agora os meios de telecomunicação evoluíram muito" (maintenant le moyen de télécommunication a beaucoup évolué). Nos anos 1970, ela notou, podia-se ficar sem notícias dos parentes por três ou seis meses, porque não havia telefones. No ano em que ela chegou, foi hospitalizada na França e chorava todos os dias porque estava cercada de "brancos" enquanto antes de sua chegada, "em casa", quando alguém via uma pessoa branca, todas as crianças fugiam de medo. Ela recorda essa experiência vividamente por causa de sua sensação de isolamento e, conseqüentemente, valoriza a capacidade tecnológica atual diversas categorias de telefone - que propicia a conexão imediata (técnica e emocional) com família.

Migrantes mais novos notaram as mesmas vantagens, bem como a possibilidade de envolver membros da família estendida em tópicos da vida cotidiana. Por exemplo, uma mulher grávida comentou que usava o telefone para discutir com sua mãe e irmãs os percalços de sua primeira gravidez. Outra mulher mencionou os benefícios de receber conselhos de tias mais velhas sobre gravidez, como lidar com o marido, dificuldades com co-esposas. Também frisou seu desejo de falar freqüentemente com suas crianças que ficaram na África para lhes dar conselhos sobre o comportamento, o respeito que deviam aos mais velhos e assim por diante.

Uma mulher, de 31 anos, deixou seu filho, hoje com 13 anos, com sua irmã no Senegal. Ela diz detestar escrever cartas (mas não se importa em recebê-las) e telefona para seu filho uma vez por semana. Ele também a chama, normalmente por 
necessidade financeira. Ele pede dinheiro para sua tia; se esta não lhe dá o suficiente para eventos da escola ou celebrações, sua mãe completa, enviando-lhe mais dinheiro pela Western Union. Essa entrevistada observa que seu filho gosta muito de telefonar para ela e pediu que ela lhe enviasse um telefone celular.

Para aqueles que não podem pagar os custos de telefonemas, a frustração é evidente. Como disse uma mulher, seu filho de quatro anos está em Mali com a avó. Ela sente saudades de seus pais e de seu filho o tempo todo e gostaria de poder telefonar, mas eles moram num povoado interiorano $e$ não possuem telefone próprio. Além disso, ela tem problemas de alojamento, nenhuma documentação $e$, em todo caso, não pode gastar dinheiro em cartões telefônicos. De forma semelhante, outra mulher deixou três filhos, de três, cinco e sete anos, com sua avó materna em Mali. Ela telefona para os garotos o quanto pode por estar muito triste sem eles. Como ela nota, telefonaria todo dia se fosse financeiramente viável.

Diversos homens comentaram como, mesmo à longa distância, desempenhavam um papel importante na tomada de decisões e na resolução de disputas na família estendida. Para aqueles que deixaram suas mulheres e crianças aos cuidados de um irmão (especialmente quando este é mais novo), chamadas telefônicas servem como meio de lidar com inveja entre esposas e crianças e reforçar a posição do migrante na família. Um migrante descreveu sua situação:

Eu deixei uma esposa em casa que fica com meu irmão mais novo e sua esposa. As mulheres não se dão e seus filhos estão sempre brigando. Meu irmão mais novo é incapaz de acalmá-los. Então eu tenho que ligar e falar com as mulheres para que elas parem de discutir.

Para alguns, a possibilidade de tal acesso imediato à família nem sempre é benéfica. Pedidos constantes de dinheiro - para cuidados com saúde, funerais, casamentos, batismos, num caso 
Migração e telecomunicações

para a reposição de gado roubado, para buscar comida representam um fardo para os imigrantes em Paris, tanto empregados como desempregados. Muitos informantes descreveram sua dificuldade em convencer seus familiares de que a vida na França não é fácil - achar trabalho, moradia adequada, criar os filhos, conseguir visto, etc. representam momentos constantes de estresse.

Família e amigos na África Ocidental formulam uma imagem da vida de imigrantes em Paris, na qual estes são bemsucedidos, financeiramente estáveis e levando uma vida invejável. Assim, um homem reclamou que seus filhos ligavam freqüentemente para pedir "tudo" - sapatos, bicicletas, os últimos estilos de vestimenta - que o seu orçamento não alcança. De fato, quase $60 \%$ dos entrevistados disseram que uma razão principal para telefonar para casa era responder a demandas por ajuda financeira; migrantes então telefonam para avisar membros da família que o dinheiro foi enviado (através da Western Union ou pela empresa de algum outro imigrante que, com sucursais em Paris e na África Ocidental, facilita a transferência de dinheiro).

Embora pedidos persistentes por auxílio financeiro representem um fardo significativo para a maioria dos migrantes, para alguns, é difícil revelar a verdade - que eles estão desempregados, desalojados, ou sem documentação -, seja por vergonha ou pelo desejo de evitar preocupações na família. Telefones, bem como um serviço de correios mais eficiente, fax e Internet, permitem uma mobilização da família na França e na África Ocidental em torno de assuntos tais como desposar ou não mais uma mulher (os mais velhos na África freqüentemente exercem pressões nesse sentido), ter ou não ter mais crianças, mandar filhos de volta à família na África ou enviar outros membros da família à França.

Como observou um migrante descontente, apesar dele ter falado à família ao longo de numerosas conversações telefônicas que não tinha quarto onde hospedar ninguém e que era muito difícil conseguir trabalho sem os papéis correspondentes, seu 
irmão mais novo recém desembarcara em Paris e sem documentação adequada. Outra migrante, uma mulher de 20 e poucos anos, com dois filhos, reclamou que a irmã de seu marido telefonava de Mali em intervalos de poucos dias. A irmã se ressentia de mudanças no comportamento do irmão após seu casamento. Antes, ele havia enviado dinheiro para casa à sua irmã e outros membros da família na África. Contudo, depois de casar, sua mulher o encorajou a economizar dinheiro na França para as crianças. Além de ligar freqüentemente por dinheiro, as chamadas da irmã também evocaram tensões conjugais, porque ela "constantemente" pergunta se a mulher de seu marido ainda não está grávida novamente. Tendo passado por duas gestações complicadas e com problemas financeiros, a mulher tinha decidido tomar pílulas anticoncepcionais, "esperando" antes de ter um novo filho. As chamadas telefônicas da irmã do marido rotineiramente provocavam discussões conjugais sobre este tema. Esse tipo de situação era raro no dia a dia das gerações anteriores de migrantes, dada a ausência de tecnologias que permitissem envolvimento mútuo nas relações familiares transnacionais.

Além das entrevistas formais que realizamos, no decorrer da observação participante na comunidade de Mali, observamos a importância das conexões telefônicas na vida diária dos migrantes. Em numerosas instâncias, vimos nossos amigos $e$ informantes oriundos de Mali ligarem de Paris para Mali para tratar de um tema tenso. Uma mulher de 24 anos, com dois filhos pequenos, telefona para sua avó diversas vezes por semana, pagando o cartão telefônico com seu salário de assistente domiciliar de saúde. Antes de casar, ela morava em Bamako, enquanto o seu então noivo trabalhava em Paris. Ele fornecia a ela um cartão telefônico para falar com ele a cada semana.

Após o casamento, esta mulher se juntou ao marido na França. Inicialmente, ele pagou por um cartão telefônico para que ela falasse com sua filha que ficara em Bamako. Contudo, depois que a filha chegou a Paris, o marido parou de pagar por cartões telefônicos para a sua mulher (embora ele os compre para si 
Migração e telecomunicações

mesmo e telefone para sua irmã, por vezes, semanalmente). Após três anos, a jovem mãe ainda se sente solitária em Paris, atravessa problemas conjugais e é confortada por contatos freqüentes com sua avó e irmão. Ela tem uma linha telefônica terrestre e um telefone celular que, boa parte do tempo, parece não estar em condições de uso. Ela pressiona sua filha de seis anos para que fale com sua avó ao telefone, esperando encorajar a criança a continuar falando Bambara. Contudo, geralmente a avó fala Bambara e a criança responde em francês, frustrando as esperanças da mãe.

Do mesmo modo, quando o marido desta jovem começou a voltar tarde na noite, dormir no sofá e receber telefonemas de uma mulher desconhecida, parentes em Mali intervieram por telefone e numa fita de áudio, lembrando ao marido de suas responsabilidades e das expectativas que tivesse uma conduta apropriada. A mulher e sua família estão convencidas de que essas chamadas e fitas persuadiram o marido a romper com seu relacionamento extraconjugal $e$ focar nas suas obrigações conjugais e parentais.

Noutros casos, nós escutamos enquanto amigas de Mali telefonavam a irmãs e filhos adultos em Bamako para discutir transações financeiras, questões de saúde e obter "notícias" em geral de vários membros da família. Essas observações informais, junto com informações de informantes, nos sugerem que telefones celulares são usados para chamadas transnacionais (seja para ou da África Ocidental) muito mais freqüentemente do que para chamadas locais.

\section{Caso 2: telecomunicações usadas em Bamako, Mali}

Entre migrantes em Paris abundavam histórias sobre aqueles que voltavam à África Ocidental com malas repletas de telefones celulares. Ironicamente ou não, a proliferação de telefones em Mali é notável: entre 2003 e 2004, o país vivenciou um crescimento de $44 \%$ nas linhas telefônicas, chegando a um 
total de 444.795; estima-se que o crescimento derive principalmente de telefones celulares (African Economic Outlook, 2005:304). De fato, telefones celulares estão rapidamente ultrapassando o número de linhas terrestres na África sub-saariana (New York Times, 2005:A8). Devido à importância que o contato telefônico evidentemente guarda para os migrantes em Paris, nos interessamos pelo crescimento exponencial nas tecnologias de comunicação acessíveis aos parentes $e$ amigos de nossos informantes parisienses. Focamos particularmente em tecnologias telefônicas, além de considerar algo da internet.

Um levantamento preliminar das cabines telefônicas $e$ vendedores de cartão telefônico na capital de Mali, Bamako, imediatamente sinalizava que o número avassalador dessas instalações traria muitas dificuldades na condução de um estudo dos usos do telefone na cidade. Num quarteirão do centro da cidade, por exemplo, encontramos uma cabine telefônica a cada 100 metros, e a venda de cartões telefônicos nas imediações. Vendedores de cartão telefônico - aqueles vendendo apenas cartões telefônicos assim como aqueles vendendo cartões telefônicos entre outras mercadorias - se localizavam lado a lado ao longo dos quarteirões centrais da cidade, bem como nos bairros do subúrbio.

Esses cartões são literalmente vendidos por toda parte: ruas, lojas de conveniência, recepções de hotéis, lavanderias, etc. Segundo um vendedor de rua entrevistado por nossa assistente de pesquisa, vendedores credenciados são incomodados por essa competição de rua, mas se sentem impotentes para agir contra ela. Contudo, um informante indicou que vendedores de rua também trabalham em colaboração com vendedores oficiais, comprando cartões deles (no valor de até $500000 \mathrm{CFA}$, o que pode representar o suprimento do mês inteiro) e em seguida dividindo os lucros.

Selecionamos um setor urbano, Comuna V, Kalaban Coura, como foco do nosso estudo. Kalaban Coura é um subúrbio da classe trabalhadora ao sul de Bamako, com uma população de aproximadamente 250.000 habitantes (Ministère de l'Administration 
Migração e telecomunicações

Territoriale, 2005). Identificamos então duas das quatro subdivisões de Kalaban Coura (Kalaban Plateau, Djallobougou, Aci, e Koko) para ter uma boa amostra desta área residencial. Residentes destas vizinhanças são principalmente Soninke e Bambara, com uma minoria de habitantes Bozo, Senufo, Songhrai, e Peuhl. Os principais empreendimentos localizados neste subúrbio são comerciais, artesanais ou pesqueiros; os residentes de uma das vizinhanças, contudo, são principalmente profissionais.

Conforme registros da comuna, Kalaban Coura como um todo inclui 118 cabines telefônicas para as quais impostos foram pagos em 2005. Estima-se que existem mais 100 cabines que não pagaram os devidos impostos e, portanto, não foram incluídas no censo de janeiro 2005. Funcionários públicos e administradores de cabines indicaram que proprietários de estabelecimentos com telefones freqüentemente estabelecem vínculos com coletores de impostos e pagam diretamente a eles, ao invés de pagar às autoridades comunais. Assim, o número de empreendimentos telefônicos pode estar significativamente subestimado, mesmo sendo estimados mais de 200 negócios - legítimos (taxados) e ilegítimos - pelo censo.

Atualmente, duas companhias telefônicas competem por clientela em Mali; Malitel (uma subsidiária de SOTELMA, estabelecida em 1989, sendo originalmente uma companhia estatal $e$ atualmente em processo de privatização) ${ }^{2}$ e Ikatel, iniciada em 2002, e subsidiária de France Telecom. Vendedores de cartões telefônicos da Malitel e da Ikatel ficam lado ao lado enquanto solicitam clientes e, da mesma forma, cabines de propriedade das duas empresas se situam a pouca distância umas das outras. Segundo o gerente de um estabelecimento da Malitel, o investimento original para a instalação da linha telefônica foi de 400000 CFA, mas nos últimos dois anos taxas de instalação caíram, de modo que tal empreendimento custaria hoje 250000

2 Em 24 de Março de 2005, a corporação multinacional Siemens anunciou planos de investir substancialmente na Malitel (afribone.com, 10/14/2005). 
CFA. ${ }^{3} \mathrm{O}$ proprietário tira um benefício de $30 \%$ por telefonema; na venda de um cartão telefônico de 2500 CFA o vendedor pode esperar um benefício de 125 CFA.

Com a ajuda de nosso assistente Moussa Keita, conduzimos a observação participante e realizamos entrevistas semiestruturadas, durante o mês de julho de 2005, em duas vizinhanças de Kalaban Coura: Kalaban Plateau e Kalaban ACI. Além das entrevistas dos autores com gerentes de cabines $e$ vendedores, Moussa Keita se envolveu em observações intensas em quatro dias de final de semana e intermitentemente em dias de semana por um período de três semanas. As duas vizinhanças eram estrategicamente selecionadas para comparação mais intensiva por Kalaban Plateau ser representativo da população de classe trabalhadora, enquanto Kalaban ACI (Agence de Cession Immobiliere) - construída pelo estado para profissionais de colarinho branco - corresponde a uma população de classe média mais alta. Um total de 17 cabines telefônicas foi enumerado em Kalaban Plateau, enquanto apenas duas foram encontradas em Kalaban ACI. Isso reflete o fato de que na subdivisão $\mathrm{ACI}$, de classe mais elevada e recentemente desenvolvida, linhas telefônicas foram instaladas e residentes têm os meios técnicos e financeiros para possuir linhas telefônicas privadas bem como telefones celulares.

Embora em Kalaban Plateau algumas pessoas também possuam linhas telefônicas, as pessoas ainda fazem chamadas de cabines, que parecem ser mais econômicas. As 17 cabines de Kalaban Plateau também vendiam cartões telefônicos. Três destes gerentes não tinham pago os impostos, admitindo terem subornado os cobradores com presentes. Entre o pessoal supervisionando as instalações telefônicas, 12 eram moças jovens, geralmente trabalhando ali como participantes mirins do investimento da sua família. Muitos dos funcionários eram graduandos da universidade e hiper-qualificados para o serviço.

3 Em janeiro de 2005, um dólar equivalia a 500 CFA. 
Migração e telecomunicações

Contudo, como um deles nos disse - uma estudante no mestrado de Direito - não há escolha: é difícil encontrar emprego melhor, então se aceita qualquer oferta que ajude a pagar as contas. Ela reclamou de seu salário, de 20000 CFA, que mal cobre seu aluguel.

Cabines telefônicas ficam ocupadas especialmente durante os fins de semana. Conforme gerentes de telefones em duas áreas, sua clientela é maior nos sábados e domingos e a maioria das ligações são para a França. Isso pode ser facilmente determinado porque os telefones possuem um mecanismo para registro dos detalhes da chamada para o cálculo dos custos. No tocante às chamadas internacionais, nosso assistente de pesquisa observou que clientes fazem um rápido telefonema e recebem uma ligação de volta de seus interlocutores, de modo a minimizarem seus próprios custos.

Alguns clientes se tornam "regulares". Um gerente de cabine nos disse que um cliente em particular vinha regularmente fazer telefonemas de 20 minutos para a França, que podem custar até 11500 CFA cada. Segundo ele, os telefonemas mais comuns duram entre cinco e sete minutos e custam 2000 a 2500 CFA. Possuir uma cabine tornou-se assim uma atividade econômica ou investimento familiar altamente rentável, um empreendimento que ganha força no processo migratório transnacional.

Embora tenhamos enfocado principalmente a utilização do telefone nesta exploração das comunicações em Kalaban Coura, também notamos a presença de dois ciber cafés na área. Dado que nossa amostra em Paris raramente usou a internet para comunicar-se com os contatos em Mali ou alhures, não nos surpreendemos de constatar que o uso da internet, apesar de ser uma prioridade governamental $e$ foco para investimentos estrangeiros, não é uma tecnologia comum para a comunicação com pessoas na França. A USAID, por exemplo, introduziu uma iniciativa para promover o uso da internet em prol do desenvolvimento sustentável em Mali. Esse programa, contudo, foi estritamente direcionado às burocracias governamentais e instituições locais especificamente ligadas à USAID (Breslar e 
Irlanda, 1996). Em 1999, quatro Provedores de Serviços de Internet estavam operando em Mali e havia um total de 750 assinantes no país. Uma lista do uso da internet por categorias incluía assinantes comerciais, acadêmicos, pesquisadores, ONGs, Nações Unidas e governo (UNECA 1999). Aparte o número limitado de ciber cafés já mencionado, o acesso a computadores é em geral limitado a contextos profissionais ou comerciais, onde a manutenção do equipamento segue sendo desafiadora.

Nossas observações em ciber cafés, diversas vezes por semana durante um mês, sugerem que (não surpreendentemente) a clientela era principalmente de estudantes, ou ex-estudantes. Todos os clientes observados tinham menos de 30 anos e, de acordo com os gerentes, são pessoas que vêm freqüentemente às lojas para jogar no computador. Não fizemos um levantamento sistemático de internet cafés pela cidade, mas visitamos mais dois em lugares diferentes, um numa área comercial próspera e outro nos arredores do mercado central. Estes dois eram maiores que aqueles em Kalaban Coura, com aproximadamente o dobro do número de computadores (10 a 12, ao invés de quatro a seis). Evidentemente, o uso da internet está relacionado à alfabetização, $e$ irá proliferar à medida que se desenvolvem políticas nacionais de educação. Ao mesmo tempo, como nas primeiras estratégias de comunicação em que migrantes solicitavam auxílio na leitura e escrita de cartas, intermediários alfabetizados hoje podem comercializar serviços de internet para clientes que necessitam de "suporte técnico". Até hoje, porém, em áreas urbanas como nas regiões rurais mais remotas, as tecnologias telefônicas são as que continuam transformando mais profundamente as relações sociais para famílias de migrantes.

\section{Conclusões}

Sinalizamos que, no contexto da migração transnacional, a proliferação de meios de comunicação entre migrantes na França, a sociedade hóspede, e suas comunidades de origem na África 
Migração e telecomunicações

Ocidental provê benefícios imediatos em termos de satisfação emocional, acesso à informação e transações diversas. Ao mesmo tempo, as tecnologias - como a crescente difusão do telefone celular - podem produzir relacionamentos familiares voláteis, à medida que, através delas, negociam-se dívidas e obrigações. Os migrantes valorizam muito a oportunidade de obter informações ágeis sobre rotinas familiares, o estado da economia doméstica e as crises de saúde. A facilidade das conexões telefônicas tornou possível o envolvimento na vida diária de parentes $e$ a manutenção de relações familiares, o que era inconcebível apenas há uma década atrás. Contudo, muitos migrantes se sentem oprimidos e freqüentemente impotentes face aos pedidos por auxílio financeiro de parentes, irmãos, filhos e amigos. Para aqueles que estão desempregados ou subempregados, demandas por ajudas financeiras são dolorosas e ainda difíceis de satisfazer. Para aqueles da África Ocidental, telefones, em especial, propiciam os meios de participar nas decisões de parentes próximos que estão espacialmente distantes. Apesar disso, conversações freqüentes não implicam necessariamente uma boa comunicação. Por diversos motivos, incluindo orgulho, vergonha $e$ responsabilidade, muitos migrantes fornecem apenas informações parciais relativas a problemas espinhosos, como a documentação oficial de imigração, alojamento, emprego $e$ estresses familiares. Por outro lado, para comunidades em Mali e outros lugares da região, a facilidade de conversações telefônicas contribuiu para um imaginário sobre a vida da comunidade africana em Paris, na qual esperanças de um futuro próspero podem permanecer viáveis.

\section{Referências bibliográficas}

AFRICAN ECONOMIC OUtLOOK. Mali. Paris, OECD, 2005.

APPADURAI, A. Modernity at Large: Cultural Dimensions of Globalization. Minneapolis, University of Minnesota Press, 1996. 
BRESLAR, Z. e IRELAND, D. Country Assessment and Implementation Strategy: Mali. USAID, Leland Information and Communication Strategic Objective Report for Mali, 1996.

BuraWOY, Michael et alii. Global Ethnography. Forces, Connections, and Imaginations in a Postmodern World. Berkeley, University of California Press, 2000.

CASTELLS, M. L'ère de l'Information: le Pouvoir de l'Identité (Tome 2). Paris, Fayard, 1999.

GIDDENS, Anthony. The Consequences of Modernity. Palo Alto, Stanford University Press, 1990.

HANNERZ, Ulf. Notes on the global ecumene. Public Culture 1(2), 1989, pp.66-75.

INDA, J.X. and ROSALDO, R. (eds.) The Anthropology of Globalization: A Reader. Oxford, Blackwell Publishers, 2002.

LOCKWOOD, Victoria (ed.) Globalization and Culture Change in the Pacific Islands. Upper Saddle River, New Jersey, Pearson/Prentice Hall, 2004.

New York Times. Cellphones Catapult Rural Africa to $21^{\text {st }}$ Century, Linking Families, Helping Farmers, August 25, 2005, A8.

Quiminal, Catherine. Gens d'Ici, Gens d'Ailleurs, Migrations Soninke et Transformations Villageoises. Paris, Christian Bourgeois, 1990.

et TimerA, Mahamet. 1974-2002. Les mutations de l'immmigration Ouest-Africaine. Hommes et Migrations 1239, 2002, pp.19-33.

SASSEN, Saskia. Globalization and Its Discontents: Essays on the New Mobility of People and Money. New York, New Press, 1999.

SMITH, M.P. and GuARNizO, L. (eds.) Transnationalism from Below: Comparative Urban and Community Research. Piscataway, NJ, Transaction Publishers, 1999.

UNECA. MALI, 1999. http://www.uneca.org/aisi/nici/country_profiles/mali/ malinter.htm. 
Figura 1

Meios de Comunicação Preferidos

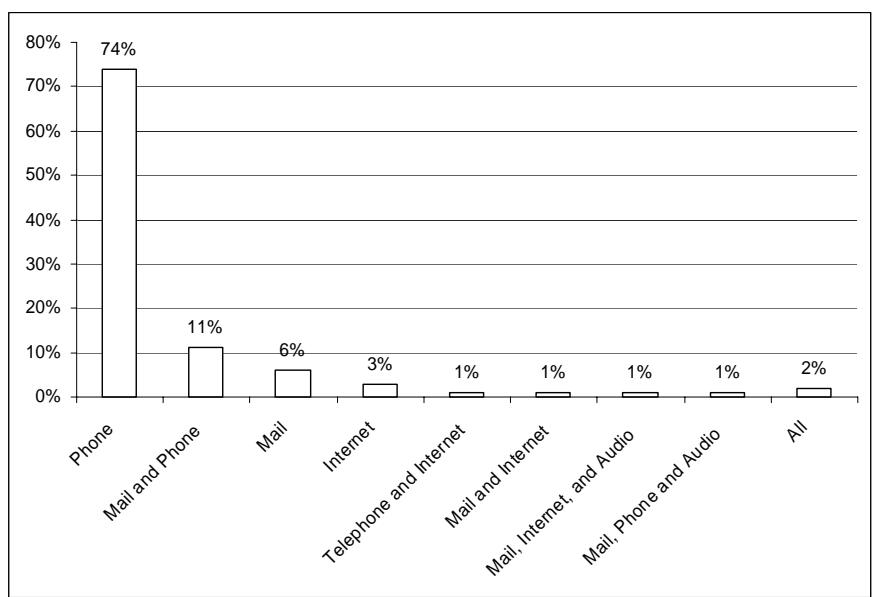

Telefone

Correio e Telefone

Correio

Internet

Telefone e Internet

Correio e Internet

Correio, Internet e Audio

Correio, Telefone e Audio

Todos

Tabela 1

Montante Expendido em Cartões Telefônicos Comparado à Situação de Trabalho

\begin{tabular}{|l|r|r|c|}
\hline $\begin{array}{l}\text { Você } \\
\text { trabalha? }\end{array}$ & $\begin{array}{c}\text { Montante } \\
\text { Expendido }\end{array}$ & \multicolumn{1}{|c|}{$\mathrm{N}$} & $\begin{array}{l}\text { Desvio } \\
\text { padrão }\end{array}$ \\
\hline Sim & 48.0385 & 39 & 35.87045 \\
\hline Não & 44.7564 & 39 & 43.64116 \\
\hline $\begin{array}{l}\text { Mercado } \\
\text { negro }\end{array}$ & 59.0000 & 3 & 78.82259 \\
\hline Total & 46.8642 & 81 & 40.98201 \\
\hline
\end{tabular}


Figura 2

Razões Para Ligar Para Casa

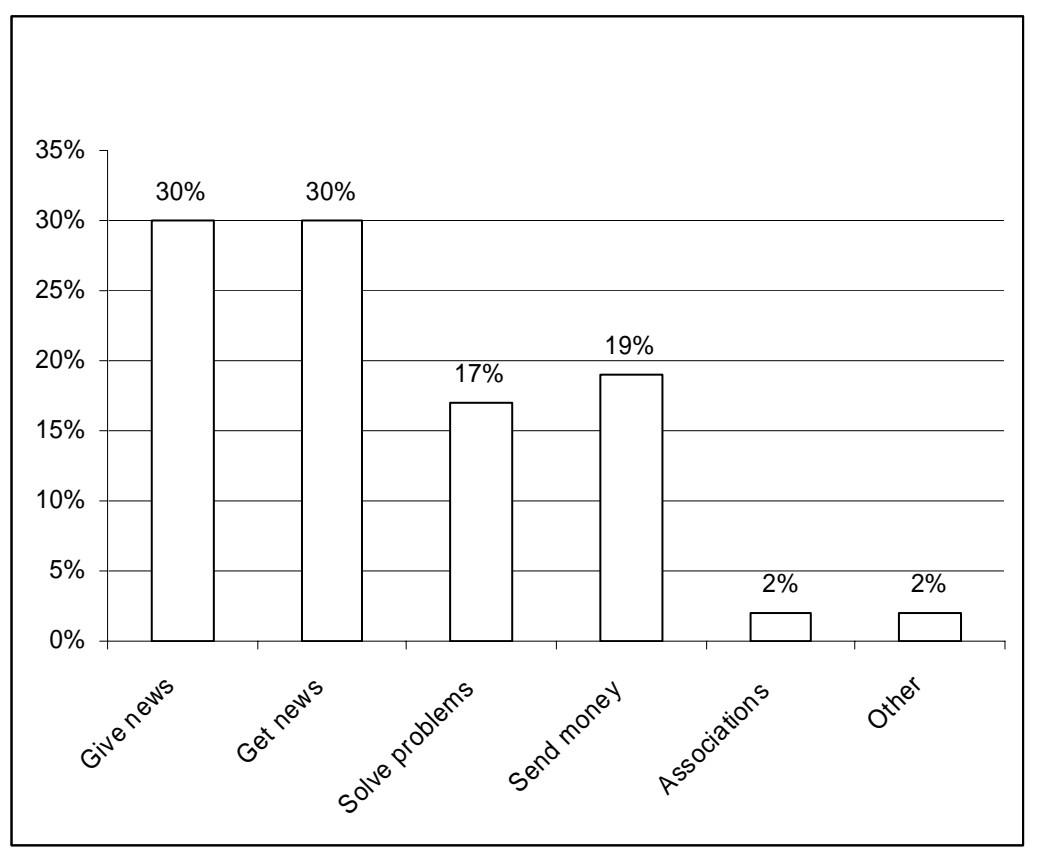

Dar Notícias

Ter Notícias

Resolver Problemas

Enviar Dinheiro

Associações

Outras 
Migração e telecomunicações

Figura 3

Chamando "Para Resolver Problemas" por Gênero

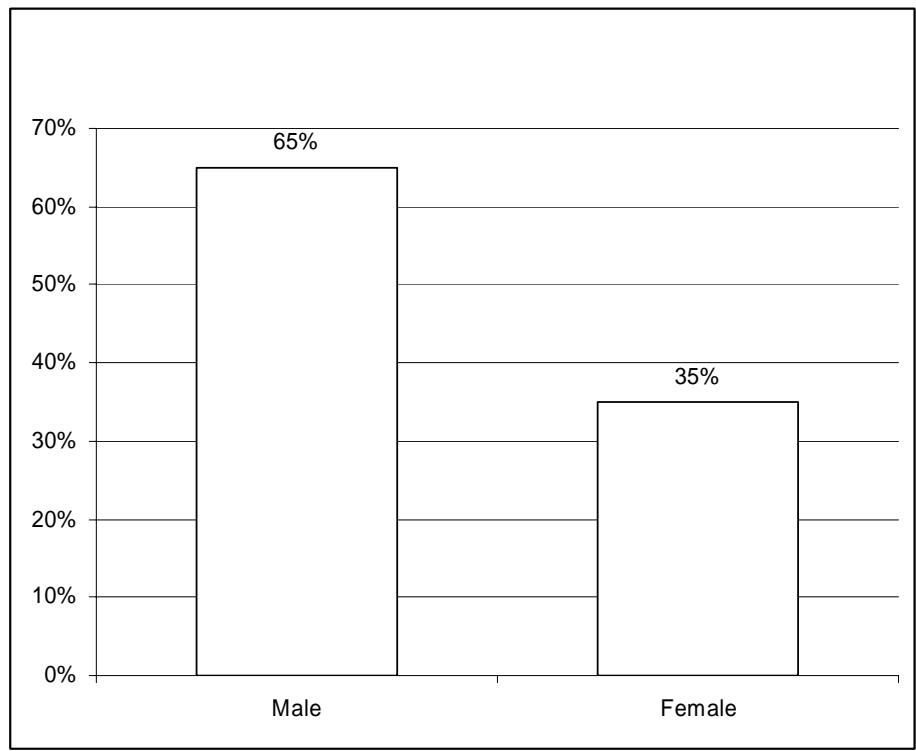

Homens

Mulheres 